月

\title{
The Harvest Time, Optimal Growth and Catharanthine Content of Catharanthus roseus Cell Aggregates Treated with Tryptophan in Erlenmeyer Flash
}

\author{
Dingse Pandiangan ${ }^{1 *}$, Wenny Tilaar ${ }^{1}$, Nelson Nainggolan ${ }^{1}$ \\ ${ }^{1}$ Sam Ratulangi University, Manado, Indonesia \\ dingsepan@unsrat.ac.id
}

\begin{abstract}
Catharanthine bioactive compounds from Catharanthus roseus L. (G.) Don has been studied either in vitro and in vivo. Studies have been conducted to determine the effect of precursor tryptophan on the optimal growth and catharanthine content produced by cell aggregate cultures of Catharanthus roseus. The optimal growth and catharanthine content occur when the aggregate cell growth is good and the content of catharanthine is also high. Aggregate cell C. roseus was cultured on Murashige and Skoog (MS) with the addition of $2 \mathrm{mg} / \mathrm{L}$ NAA and $0.2 \mathrm{mg} / \mathrm{L}$ kinetin. Treatment was given with the addition of $150 \mathrm{mg} / \mathrm{L}$ tryptophan and the control without tryptophan. Further, the growth and the content of catharanthine were observed in cell aggregates and the medium on day $0,4,7,10,14$, and day- to- 21 . Catharanthine content analysis was conducted using High-Performance Liquid Chromatography (HPLC) using a VP-ODS column C-18. The optimal growth was different in control and that $150 \mathrm{mg} / \mathrm{L}$ treatment tryptophan of cell aggregates and tryptophan may improve the growth and lead to longer growing phase after treatment compared with controls. The growth and catharanthine content are the highest after the tryptophan treatment on cell aggregates occurred on day 14 with the content of $2261.68 \pm 17.05 \mathrm{mg} / \mathrm{g} \mathrm{DW}$. Subculture and harvest time are the best cells on day 14 after culture, and on day 14 the highest catharanthine content and biomass were obtained. The results of this study are needed to determine the appropriate harvest time on the production of secondary metabolites of catharanthine by in vitro. For future research, the optimal growth and content of catharanthine on the 14th day of culture in the bioreactor in a large scale or industries should be observed.
\end{abstract}


The Harvest Time, Optimal Growth and Catharanthine Content of Catharanthus ...Pandiangan et al.

\section{Introduction}

Indonesia has the second largest biodiversity in the world after Brazil. It is known as a megabiodiversity area. Indonesian plant diversity also becomes a priceless asset. According to the estimation of the World Health Organization, $80 \%$ of the world population still rely on treatments using drugs derived from plants. Even a quarter of modern medicines circulating in the world comes from an active ingredient isolated and developed from plants (Tripathi and Tripathi, 2003). Secondary metabolites have long been used as raw materials for chemical compounds, such as flavorings, cosmetics, and pharmaceutical raw materials; even more, than $60 \%$ of essential drugs in the world are made from pure extracts of secondary metabolites produced by various plant species (Scragg, 1994). One of the plants used as a raw material medicine is Catharanthus roseus. This plant produces more than 130 kinds of alkaloids. One of them is vinblastine, the condensation of vindoline and catharanthine, which is efficacious as anticancer drugs (van der Heidjen et al., 2004). One of the major constraints faced by the pharmaceutical industry in producing vinblastine is the low content in the plant (about 0.0003\%); it should not be made from synthetic compounds (van der Heidjen et al., 2004, El Sayed et al., 2004). However, the results showed that the semisynthetic vinblastine can be created, which is by dimerization catharanthine and vindoline using peroxide (Van der Heijden et al., 2004, El Sayed et al., 2004). The synthesis of vinblastine requires vindoline and catharanthine. Vindoline can be extracted directly from plants; the content in the plants is about $0.2-0.5 \%$ (Misawa, 1994; Sutarno \& Rudjiman, 2003). Meanwhile, very low catharanthine content is found in plants (Vanisree et al., 2004). Therefore, more research leads to increased production of catharanthine (Pandiangan et. Al., 2013).

Production of secondary metabolites with the conventional method has several weaknesses; it requires a lot of raw materials, vast land, a little production. It is also strongly influenced by environmental factors such as climate change and pathogens. Tissue culture methods can be used as an alternative method for producing secondary metabolites (Vanisree et al., 2004, El Sayed et al., 2004). However, many studies have reported that secondary metabolites produced in some plant cultures are still low. Therefore, in recent years, various strategies have been used to increase the production of secondary metabolites using tissue culture techniques. One of which is with the addition of a precursor directly into the medium (Luckner and Diettrich, 1990). Based on the above description, research on the influence of tryptophan on growth and increased content of catharanthine in aggregate cultures of Catharanthus roseus cells was conducted.

\section{Materials and Methods}

\subsection{Research Materials}

The plants used as the source of explants in this study are Catharanthus roseus (L.) G. Don a white flower. These plants were grown in the greenhouse Botanical Laboratory, Sam Ratulangi University of Manado, Indonesia. The leaf explants that are used for callus induction are leaves that grow actively, among others 3rd and 4th leaves from the shoot apex (Pandiangan and Nainggolan, 2006). 
The Harvest Time, Optimal Growth and Catharanthine Content of Catharanthus ...Pandiangan et al.

\subsection{Callus Induction and Culture}

The method used for callus induction follows the method of Pandiangan and Nainggolan (2006). Leaf explants were sterilized by soaking them in $70 \%$ alcohol for 1 minute. Then, they have soaked a solution of sodium hypochlorite $(\mathrm{NaClO}) 0.525 \%$ for 10 minutes. The explants that had been sterilized were left and cut to the size of $0.5 \times 0.5 \mathrm{~cm}^{2}$ in the transfer box, and then implanted into the solid MS medium added with growth regulators of $1.5 \mathrm{mg} / \mathrm{L} \mathrm{2,4-D}$ and $0.15 \mathrm{mg} / \mathrm{L}$ kinetin (Pandiangan et al., 2011). The culture was then stored in a culture rack at room temperature of $25^{\circ} \mathrm{C}$. Callus which was used at this stage was 4 months old, or about 16 weeks. Callus was subcultured on media production. Medium production was the basis of callus induction medium with growth regulator $2 \mathrm{mg} / \mathrm{L}$ NAA and $0.2 \mathrm{mg} / \mathrm{L}$ kinetin (Pandiangan et al. 2013). Callus cultures were incubated at room temperature.

\subsection{Aggregate Cell Culture}

After 16 weeks, the callus was transferred to MS liquid medium and added with $2 \mathrm{mg} / \mathrm{L}$ NAA, 0.2 $\mathrm{mg} / \mathrm{L}$ kinetin, and $150 \mathrm{mg} / \mathrm{L}$ tryptophan for treatment. The control medium was without the addition of tryptophan. Heavy callus used was $1 \mathrm{~g}$ to one $100 \mathrm{~mL}$ Erlenmeyer flask containing $25 \mathrm{~mL}$ medium. Cell aggregate cultures were incubated at room temperature and agitated at $120 \mathrm{rpm}$ (Pandiangan et al., 2008).

\subsection{Growth Measurement of Cell Aggregates}

The cell aggregates formation process Cultures were observed visually (Pandiangan et al., 2006). Cell aggregate Cultures that have been given the treatment and control were carried out on days 0,4 , $7,10,14$, and 21 after culture. Cell aggregates in the freeze dryer were dried and weighed to obtain the dry weight, both treatment, and control. The dried cell aggregates were then used as a sample to determine the content of catharanthine in the next procedure (Pandiangan et al., 2015).

\subsection{Determination of Catharanthine Content C.roseus Cell Aggregates}

The method used for determining the catharanthine content follows Pandiangan et al. (2015). Callus samples were dried using the freeze dryer until they reached a constant weight. A total of 0.1 grams of dried callus was crushed and dissolved in $10 \mathrm{~mL}$ methanol analytical. The samples were agitated for 4 hours at a speed of $120 \mathrm{rpm}$. The mixture was separated using Whatman filter paper no. 1 . Then, the methanol extract was evaporated at a temperature of $250 \mathrm{C}$ during the day. The evaporation residue was dissolved in $2 \mathrm{~mL}$ of methanol HPLC, ready for analysis.

Catharanthine content analysis was performed using quantitatively and qualitatively using HighPerformance Liquid Chromatography (HPLC). The mobile phase used as eluent was a solution consisting of methanol, acetonitrile, and $5 \mathrm{~mm}$ diammonium hydrogen phosphate with a ratio of 3: 4: 3 in isocratic. The flow rate was $1 \mathrm{~mL} / \mathrm{min}$. The type of column used was Shimpac VP-ODS C18 $150 \mathrm{x}$ $4.6 \mathrm{~mm}$. The wavelength used to detect catharanthine was $220 \mathrm{~nm}$.

\subsection{Data Analysis}

Data analysis to determine the effect of treatments was performed using analysis of variance (ANOVA) in a completely randomized design (CRD) with a factorial of $95 \%$. If real differences were found, it was then followed by a post hoc test DMRT (Duncan's Multiple Range Test) at a 95\% confidence level in program Statistica release 6 (Steel and Storrie, 1995). 
The Harvest Time, Optimal Growth and Catharanthine Content of Catharanthus ...Pandiangan et al.

\section{Results and Discussion}

\subsection{The Growth of C. roseus Cell Aggregates Treated with Tryptophan}

Cell aggregate cultures obtained from the callus cultures were transferred into liquid MS medium with the addition of $2 \mathrm{mg} / \mathrm{L}$ NAA and $0.2 \mathrm{mg} / \mathrm{L}$ kinetin (Figure 1A). Cell aggregates were cultured in the medium by shaking at $120 \mathrm{rpm}$ (Figure 1). Shuffle function is to distribute the cells evenly in the medium (Bhojwani and Razdan. 1983). So, the culture will get the same nutrients. Aggregate cultures of cells that have acquired cell sizes range from a single cell to cell aggregates with a diameter of $2 \mathrm{~mm}$ (Mattel and Smith, 1983). Aggregate cell culture represents a natural or immobilized cell, also called NICS (Naturally immobilized Cell System) with low cell growth and secondary metabolite production compared to cell suspension (Lindsey and Yeoman, 1983). This is due to the position of dense cells in cell aggregates which may limit cell division and take nutrients from the medium, but it can enhance chemical and physical interactions between cells, forming conditions that resemble normal conditions in intact plants (El Sayed et al., 2004).

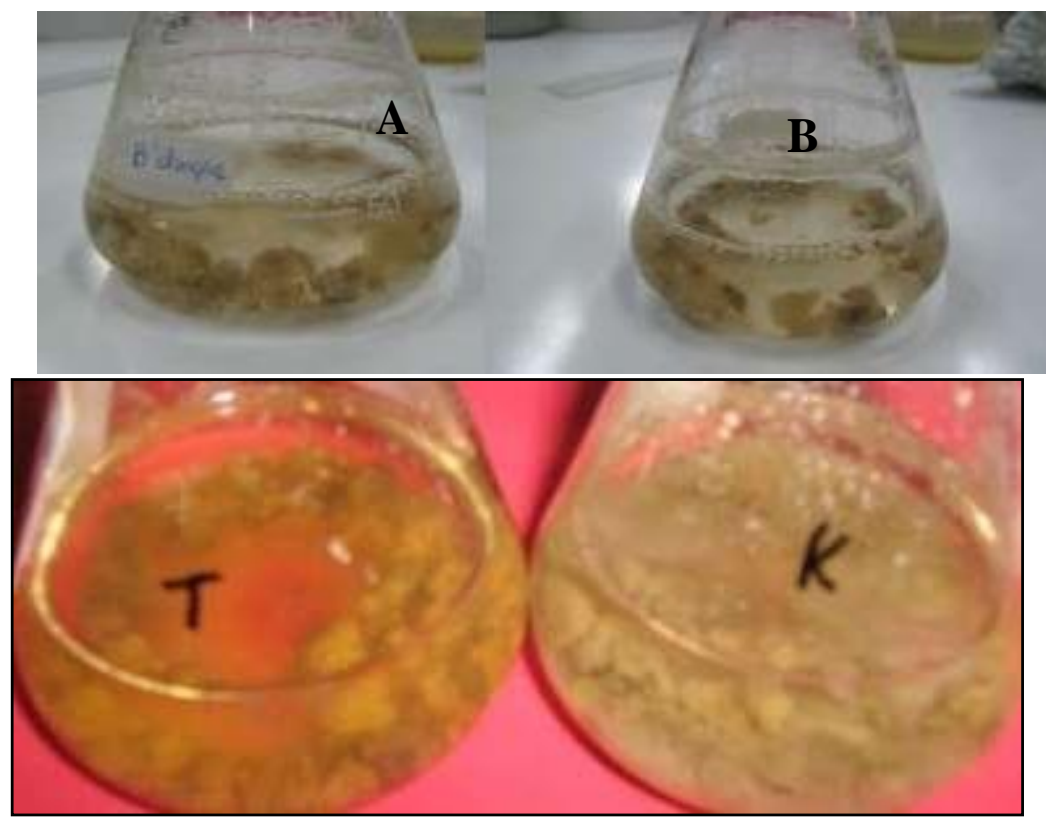

Figure 1: C.roseus cell aggregate cultures in MS liquid medium. A. Control culture of cell aggregates to a 4-day. B. Cell aggregate cultures day-to-4 treatment tryptophan. $\mathrm{K}=$ cell aggregate cultures of control after 14-day cultured. $\mathrm{T}=$ cell aggregate cultures treated after 14-day cultured.

Verpoorte et al. (2000) reported that the aggregate cultures of $C$. roseus have advantages in the regulation of tryptophan decarboxylase, which is an important factor in the biosynthesis of terpenoid indole alkaloids. Cell aggregates were subcultured every 14 days of culture. Subcultures were performed with removal of old medium with new medium similar in terms of the composition to the previous medium. Subcultures in the new medium gave rise to the gas exchange between air and cell aggregates in the medium and provided new nutrients to the cell aggregates (Bhojwani and Razdan, 1983).

Tryptophan treatment can affect cell aggregate growth directly or indirectly (Pandiangan, et al., 
The Harvest Time, Optimal Growth and Catharanthine Content of Catharanthus ...Pandiangan et al.

2012). The direct effect of precursor tryptophan on cell growth is through the synthesis of proteins in cells by using one of the amino acid tryptophans in the formation of polypeptides or proteins (Lehninger, 1990). It is influenced indirectly through the synthesis of auxin (Dahab and El-azis, 2006) because tryptophan acts as a precursor in the biosynthesis of IAA in the tryptophan path independent (Fosket, 1994). Moursy et al. (In Dahab and El-Azis, 2006) have investigated the influence of tryptophan on callus dry weight Datura stramontum tryptophan treatment would cause an increase in the amount of endogenous IAA. Furthermore, the IAA will induce cell division, so that cell growth is enhanced. Verpoorte et al., (2000) states that the addition of tryptophan can lead to overexpression of TDC-gene. TDC activity in cell aggregates $C$. roseus is at a high linear phase, leading to increased accumulation of tryptamine, which could increase the wet weight of cell aggregates (Facchini and DiCosmo, 1991). The effect of various concentrations of the tryptophan on the growth of cell aggregates can be obtained from the next study.

Data cell aggregate culture growth or the average dry weight of aggregate in the control and treatment of $150 \mathrm{mg} / \mathrm{L}$ tryptophan are presented in Table 1 . The result of a one-way ANOVA test with a 95\% confidence level showed the dry weight of the control callus with treatment, which was significantly different. The growth curve of dry weight measurements shows the pattern of cell aggregates as presented in Figure 2. The growth curve shows that the growth pattern of cell aggregate culture of control and the treatment is in a similar lag phase and both occurred on day 4. At this lag phase, cells have a physiological adaptation to new surroundings and start to continue the cell division of cells in the log phase (Endress, 1994).

The analysis of variance test results in Table 1 and Figure 2 shows that there are significant differences between the pattern of aggregate growth of cells without treatment tryptophan (control) and with tryptophan treatment. The real difference between the two aggregate growth patterns of tryptophan and without tryptophan treatment in the logarithmic or linear phase of cell aggregate is that the optimum harvest time or growth with tryptophan treatment is longer than the control (Pandiangan et al., 2015). The stationary phase in the control cell aggregates occurred starting from day 10 while in treatment it occurred on day 14 (Figure 2). Therefore, tryptophan treatment can extend the subculture and is very useful in storage or stock cells during production (Mandagi et al., 2017).

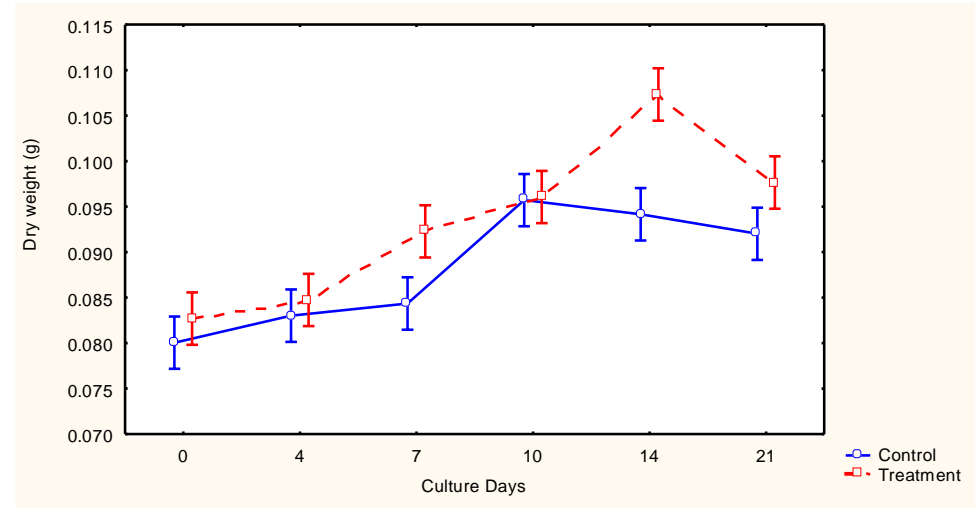

Figure 2: Catharanthus roseus cell aggregate growth curve of control and treatment of tryptophan $150 \mathrm{mg} / \mathrm{L}$. 
The Harvest Time, Optimal Growth and Catharanthine Content of Catharanthus ...Pandiangan et al.

\begin{tabular}{ccc}
\hline \multirow{2}{*}{ Culture Age (day) } & \multicolumn{2}{c}{ Dry Weight $(\mathrm{g})$} \\
\cline { 2 - 3 } & Control \pm SD & Treatment \pm SD \\
\hline 0 & $0.080 \pm 0.002^{\mathrm{a}}$ & $0.083 \pm 0.001^{\mathrm{ab}}$ \\
4 & $0.083 \pm 0.001^{\mathrm{ab}}$ & $0.085 \pm 0.001^{\mathrm{b}}$ \\
7 & $0.084 \pm 0.001^{\mathrm{ab}}$ & $0.092 \pm 0.002^{\mathrm{c}}$ \\
10 & $0.096 \pm 0.003^{\mathrm{cd}}$ & $0.096 \pm 0.006^{\mathrm{cd}}$ \\
14 & $0.094 \pm 0.001^{\mathrm{cd}}$ & $0.107 \pm 0.003^{\mathrm{e}}$ \\
21 & $0.092 \pm 0.001^{\mathrm{c}}$ & $0.098 \pm 0.002^{\mathrm{d}}$ \\
\hline
\end{tabular}

Table 1: Average dry weight $(\mathrm{g})$ of $C$. roseus cells aggregate treated with tryptophan $150 \mathrm{mg} / \mathrm{L}$ and control

Note: - The value above is the average dry weight of aggregates of cells \pm standard deviation (SD).

- Value followed the same letters indicates not significantly different based on the Duncan test with a level of confidence $95 \%$.

- The blue box represents the highest catharantine content and is significantly different from the other culture days at a significance level of 5\%

Figure 2 indicates that control cell aggregates have a lag phase of day-to- 0 until the 4 th, then the acceleration phase on day 4 through the 7 th, the next $\log$, or exponential phase occurred from day 7 to day-to-10, stationary phase or phases ultimately senescence after a day-to-10. In cell aggregate cultures with the addition of $150 \mathrm{mg} / \mathrm{L}$ tryptophan, the phase lag day 0 to the 4th, then the acceleration phase at around day 4. This phase is shorter than the control. The next log or exponential phase occurred from day-to- 4 to day 14 , eventually stationary phase or phases senescence after day 14 . In the control cell aggregate, the stationary phase occurred faster than in the four days of treatment. It is predicted that the addition of tryptophan precursors will lead to cell growth in a long linear phase, from days 4 to 14 , because tryptophan is available to synthesize enough protein for growth of callus and also to other interests in the metabolism of vinca cell aggregates. C. roseus cell aggregate growth curve of control and treatment of tryptophan showed a difference.

Different patterns of growth control cell aggregate culture and treatment lie in the acceleration phase, the log, and stationary (Pandiangan et al., 2015). In the acceleration or the acceleration phase, cell growth and increased cell count are high enough, because, at this phase, the cell has to adapt to the environment and get enough nutrients from the medium (Pandiangan et al., 2008). The acceleration phase of the cell aggregates may be more short-tryptophan treatment, but because the dry weight measurement was not done every day, it does not appear in the data (Pandiangan et al., 2006). Longer logarithmic or exponential phase cells of tryptophan treatment possibilities are estimated at day 4 to 14 (Pandiangan et al., 2008). Furthermore, in the stationary phase, cells will decrease in terms of the amount of nutrient medium because of the diminishing and the possibility of waste substances that are toxic to cells (Moreno-Valenzuela et al., 1999). Walton et al. (1988) extended that Cadapherin alkaloids in Nicotiana rustica root cultures have toxic effects on cells. Therefore, the accumulation of alkaloids in the late stationary phase culture of cell aggregates is believed to be the cause of the decline of cells. Stationary phase cells of tryptophan treatment are longer than the control achieved.

\subsection{Catharanthine Content of Cell Aggregates that Treated Tryptophan}

Catharanthine contents in cell aggregates were significantly different in treatment. The content of tryptophan treatment cell catharanthine is also higher than the controls on each day of observation (Table 2 and Figure 3). In general, the differences from the control treatment was on day 4; the 
The Harvest Time, Optimal Growth and Catharanthine Content of Catharanthus ...Pandiangan et al.

catharanthine content of control decreased, whereas the treatment did not differ from day-to- 0 (Pandiangan et al., 2012). Likewise, the real difference in the best content of catharanthine occurred in the control occurred after 10 days of culture $(2026.86 \pm 12.05 \mathrm{~g} / \mathrm{g} \mathrm{DW})$ while the highest content of tryptophan treatment occurred after the 14 th day of culture $(2261.68 \pm 17.05 \mathrm{~g} / \mathrm{g} \mathrm{DW})$. The details can be seen in Table 2 .

The highest content of cell aggregate culture catharanthine on tryptophan treatment occurred on day 14 after culture. This supports that day 4-to-14 is an early stage of the stationary phase of the growth curve (Pandiangan et al., 2015). According to Endress (1991), the highest accumulation of secondary metabolites $C$. roseus serpentine occurred in the early stationary phase of the growth curve. The high content of catharanthine in these phases is also associated with the activity of TDC (Facchini and DiCosmo, 1991). This will be proved in the next stage of research.

\begin{tabular}{ccc}
\hline \multirow{2}{*}{ Culture Age (day) } & \multicolumn{2}{c}{ Dry Weight $(\mathrm{g})$} \\
\cline { 2 - 3 } & Control \pm SD & Treatment \pm SD \\
\hline 0 & $1874.19 \pm 17.07^{\mathrm{b}}$ & $1874.19 \pm 17.07^{\mathrm{b}}$ \\
4 & $1791.29 \pm 14.91^{\mathrm{a}}$ & $1898.09 \pm 5.48^{\mathrm{b}}$ \\
7 & $1896.25 \pm 4.44^{\mathrm{b}}$ & $2085.32 \pm 31.07^{\mathrm{f}}$ \\
10 & $2026.86 \pm 12.05^{\mathrm{e}}$ & $2144.48 \pm 30.92^{\mathrm{g}}$ \\
14 & $1984.40 \pm 6.55^{\mathrm{d}}$ & $2261.68 \pm 17.05^{\mathrm{h}}$ \\
21 & $1944.08 \pm 30.64^{\mathrm{c}}$ & $1985.13 \pm 21.93^{\mathrm{d}}$ \\
\hline
\end{tabular}

Table 2. The average catharanthine content $(\mu \mathrm{g} / \mathrm{g} \mathrm{DW})$ in the aggregate C.roseus cells treated with $150 \mathrm{mg} / \mathrm{L}$ tryptophan and control.

Note: - The value above is the average catharanthine content $(\mu \mathrm{g} / \mathrm{g} \mathrm{DW})$ of aggregates of cells \pm standard deviation (SD).

- Value followed the same letters indicate not significantly different based on the Duncan test with a level of $95 \%$

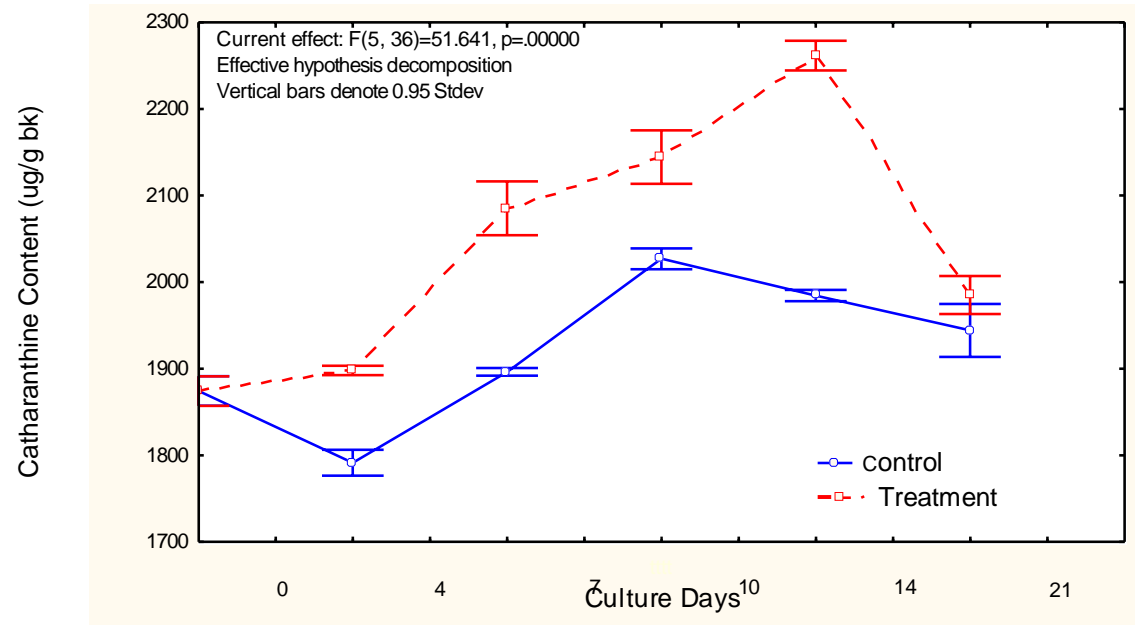

Figure 3: Curve catharanthine content ( $\mu \mathrm{g} / \mathrm{g} \mathrm{DW})$ in cell aggregates treated C.roseus $150 \mathrm{mg} / \mathrm{L}$ tryptophan and control. 
The Harvest Time, Optimal Growth and Catharanthine Content of Catharanthus ...Pandiangan et al.

The relation between best growth and highest content catharanthine in cell aggregate culture is considered to obtain the optimum condition for next step research or culture with large volume likely bioreactor and the pharmaceutical industry. Once both parameters are linked (Tables 1 and 2), subculture should be done on day 14, and preferably also treated cell aggregates harvested at day 14 after subculture (Pandiangan et al., 2015). It is important to keep the cells continue to grow without having to adapt to the longer lag phase. Likewise, the harvested cell for the production of catharanthine should be used after 14 days of tryptophan treatment and control (Pandiangan et al., 2013). The decrease of catharanthine content after day 14 of treatment and control on day-to-10 can also be caused by the secretion of catharanthine to the culture medium (Pandiangan et al., 2013). Nijkamp et al. (1990) explain that several secondary metabolites produced by the cells will be secreted to the medium. Likewise, Drapeau, et al. (1987) reported that the addition of succinic acid also increased the alkaloid ajmalicine up to five times, the increase was more than $78 \%$ of the total ajmalicine and $67 \%$ of total serpentine was released into the medium. There is a possibility that after the stationary phase, catharanthine was released into the medium (Pandiangan et al., 2006). Thus, compounds within the cell aggregate were reduced (data not shown).

These results strengthen the hypothesis that the addition of tryptophan precursor C. roseus cell aggregates in Erlenmeyer culture medium can affect the optimum growth and catharanthine content. The effect generated is also significant and has a positive effect; an increase occurs and the morphology is better (Pandiangan et al., 2012). The results of this study are needed to determine the appropriate harvest time on the production of secondary metabolites of catharanthine by in vitro (Mandagi et al., 2017; Pandiangan et al., 2015).

\section{Conclusion}

It can be concluded that the optimal growth was different in control and that $150 \mathrm{mg} / \mathrm{L}$ treatment tryptophan of cell aggregates and tryptophan may improve the growth and lead to longer growing phase after treatment compared with controls. The growth and catharanthine content are the highest after the tryptophan treatment on cell aggregates occurred on day 14 with the content of $2261.68 \pm 17.05$ $\mathrm{mg} / \mathrm{g}$ DW. Subculture and harvest time are the best cells on day 14 after culture, and on day 14 the highest catharanthine content and biomass were obtained. The results of this study are needed to determine the appropriate harvest time on the production of secondary metabolites of catharanthine by in vitro. For future research, the growth and content of catharanthine on the 14th day of culture in the bioreactor in a large scale or industries should be observed.

\section{Acknowledgments}

The authors would like to thank the Head of the Laboratory of the Faculty of Agriculture Sam Ratulangi University for his help and facility so that that research can be completed. Also, the authors wish to thank the Directorate General of Higher Education for funding the research through grant no. 042.06.1.401516/2016 dated December 7th, 2015.

\section{References}

Dahab TAMA and El-Aziz NGA. (2006). The Physiological effect of diphenylamine and tryptophan on the growth and chemical constituents of Philodendron erubescens plants. WJAS 2 (1): 
The Harvest Time, Optimal Growth and Catharanthine Content of Catharanthus ...Pandiangan et al.

75-81

El-Sayed M, Choi YH, Frederich M, Roytrakul S, Verpoorte R, 2004. Alkaloid accumulation in Catharanthus roseus cell suspension cultures fed with Stemmadenine. Biotechnol Lett. 26: $793-798$.

Endress R 1994. Plant Cell Biotechnology. Springer-Verlag Berlin Heidelberg. New York. p.67.

Facchini PJ and DiCosmo F, 1991. Secondary metabolite biosynthesis in cultured cells of Catharanthus roseus (L.) G. Don immobilized by adhesion to glass fibers. Appl Microbiol Biotechnol 35:382-392. York

Fosket DE. 1994. Plant Growth and Development. A Molecular Approach. Academic Press. New

Gaines J, 2004. Increasing alkaloid production from Catharanthus roseus suspension through methyl jasmonate elicitation. Parm. Engineer. 24: 106-123.

Islas I, Loyola-Vargas VM, and Miranda-Ham ML, 1994. Tryptophan decarboxylase activity in transformed roots from Catharanthus roseus and its relationship to tryptamine, ajmalicine, and catharanthine accumulation during the culture cycle. In Vitro Cell. and Dev. Biol. 30(1): 81-83.

Lehninger AL, 1990. Principles of Biochemistry 4th Edition. DL Nelson and MM Cox (Eds). pp.78-80, 147-, 671-680, Worth Publisher, Inc.

Lindsey K and Yeoman MM, 1983. Novel Experiment System for Studying to Production of Secondary Metabolites by Plant Tissue Culture. In. S. H. Mantell and H. Smith. Plant Biotechnology. Cambridge University Press. London

Mandagi SJM, Pandiangan D, and Tilaar, W. 2017. The Content of ajmalicine on cultured callus Catharanthus roseus (L.) G. Don with tryptophan treatment. IJSR 6 (3) p.1919-1922

Mattel SH and Smith H, 1993. Cultural factor that influences secondary metabolites accumulation in plant cell and tissue cultures. In: Plant Biotechnology. S.H. Mattel and H.Smith (Eds). CambridgeUniversity. London. P. 75-102.

Moreno-Valenzuela O, Coello-Coello J, Loyola-Vargas VM, and Vazquez-Flota FV, 1999. Nutrient consumption and alkaloid accumulation in a hairy root line of Catharanthus roseus. Biotechnol. Lett. 21: 1017-1021.

Nijkamp HJJ, Van der Plas LHW, van Aartrijk J, 1990. Progress in Plant Cellular and Molecular Biology. Current Plant Science and Biotechnology in Agriculture. Kluwer Academic Publishers. The Netherlands.

Pandiangan D and Nainggolan N, 2006. The Enhancement of Catharanthine Content in Catharanthus roseus Callus Culture Treated with Naphthalene Acetic Acid. Hayati Journal of Bioscience 13(3): 89-94 (in Indonesian).

Pandiangan D, Esyanti RR, Usviany V and Wulansari W, 2008. Production of Catharanthine in Catharanthus roseus Aggregate Cell Cultures by Feeding, Elicitation and Immobilization Method. In Proceedings of ICMNS, Bandung, Indonesia pp. 379-386.

Pandiangan D, Rompas D, Aritonang H, Esyanti R, and Marwani E, 2006. The Influence of Tryptophan on Growth and Catharanthine Content in Catharanthus roseus Callus Culture, JMS 11: 111-118 (in Indonesian).

Pandiangan D, Tilaar W and Nainggolan N, 2012. The Correlation of Cell Specialization with IAA Content of Catharanthus roseus Cell Culture by the Addition of Tryptophan. EUGENIA 18: 140-149 (in Indonesian).

Pandiangan D, Tilaar W and Nainggolan N, 2013. Morphological Changes of Cell in Relation to Increased Catharanthine Content of Catharanthus roseus Cell Aggregate Culture after Tryptophan Treatment. International Journals of Basic \& Applied Sciences. 13 (1) p.44-50.

Pandiangan D, Tilaar W, Karyono, Esyanti RR and Subarnas A, 2011. The Growth, Protein Content and TDC Activity Responses of Catharanthus roseus (L) G. Don Cell Aggregate Culture that Feeding Tryptophan. BIONATURA 13: 16-25. (in Indonesian).

Pandiangan D, Tilaar W, Nainggolan N and Wahyudi L, 2015. Relations between Catharanthine Content Enhancement with the Other Associated Secondary Metabolites in Catharanthus roseus Cell 
The Harvest Time, Optimal Growth and Catharanthine Content of Catharanthus ...Pandiangan et al.

Culture that Treated Tryptophan. IJSR .4 (11):2208-2212.

Scragg AH, 1994. Bioreactors for The Mass Cultivation of Plant Cell. In: Fowler, M. W., Warren, G. S., and Moo-Young (Ed). M. Plant Biotechnology. Pergamon Press. Inc. New York. p.49-62.

Steel RGD dan Torrie JH, 1995. Principles and Procedures Statistics. A Biometric Approach, Second Edition, PT. Gramedia Pustaka Utama, Jakarta (in Indonesian)

Sutarno H and Rudjiman, 2003. Plant Resources of Southeast Asia No 1. Medicinal and Poisonous Plants, Baclihuys Publishers, Leiden.

Tripathi L and Tripathi JN, 2003. Role of biotechnology in medicinal plants. Tropical J. Pharm Res. 2(2): 243-253.

Van der Heijden R, Jacobs DI, Snoeijr W, Hallard D, and Verpoorte R, 2004. The Catharanthus Alkaloid: Pharmacognosy and Biotechnology. Curr. Med. Chem. 11: 607-628

Vanisree M, Lee CY, Lo SF, Nalawade SM, Lin CY, and Tsay HS, 2004a. Studies on The Production of Some Important Secondary Metabolites 1. Bot. Bull. Acad. Sin. 45: 1-22.

Verpoorte R, van der Heijden R and Memelink J, 2000. Engineering the plant cell factory for secondary metabolite production. Trans. Res. 9: 323-343.

Walton NJ, Robins RJ, Rhodes MJC, 1988. Perturbation of alkaloid production by cadaverine in hairy root cultures of Nicotiana rustica. Plant Sci. 54: 125-131. 